\title{
PARA UNA RETÓRICA DE LA PARADOJA
}

\author{
Fernando Romo
}

FI anterior eprigrafe quicre recordar, como el lector advertirá, la conocida Retirica de la ironia de Wayne Booth '. Pero fiente a la copiosa bibliogralía consalgrada al tropo de Booth, nuestra fïgura no ha corrido la misma suerte. Aunque no siempre fue así: clesde Aristóteles. no hay retórica antigua o clásica que no atienda a la figura, que se convierte en una de las claves de la Agudeza y Arte de Ingenio de (iacián o de las Instituziomi Oratorie de Vico.

Otro lanto podría decirse en el ámbito de la lógica descle el Sofista platónico o los Tópicos aristótclicos, con un importante resurgir en nuesmo siglo a partir de la investigación lógica y matemática de Frege o de Russell y Whitchead.

Para la retórica contemporánea’ puecle resultar interesante el estudio de una figura que obliga a considerar la tradición retórica, amplía unos estudios elocutivos la "retórica restringidan-- casi confinados en el ámbito de la metátora y la metonimia, y. finalmente, frente a la reitcración de llamamientos en favor de una nueva teoría más general y comprelonsiva, hace avan\%ar en el terreno empírico.

Precisamos una concepción de la paradoja lo bastante flexible como para recoger las diversas prácticas discursivas socialmene vivas. De alı́ que la mayor parte de mis ejemplos

1.- BOOTH, Wayne, A Rheroric of homs. University of Chicago Press. 1974. Hay version española: Relibrica de la iromia. Madrid, Taurus, 1986.

2.- Para el conflicto entre las diversas direcciones réricias, véalse PO\%.JELO YVANCOS, José M.A Del formalismo a la menretórica. Madrid. Taurus. 1988: y las actas del seminatro organizado por el Centro Baropeo de Estudios Argumentativos: MEYER, Michel, LAMPI:RI:UR. Alain (eds.), Fïgures et conflits rhéloritums. Université (le Bruxelles, 1990). 
procedan de la prensa diaria. con la esperanza de que sobre este fondo destacalrá más clanamente la peculiariclad de muchas paradojas literarias.

En la Agudeza y arte de ingenios', (iracián se sirvió como ejemplo de paradoja de una naración completa, el ensiemplo XV del Conde l.ncanor En efecto. con el mismo derecho con que Jakobson asociaba la metonimia con la prosa y el realismo, podemos reconocer una invención o una disposición paradójicals en narraciones enteras. Baste recordar til curioso impertineme: I.otario engaña a Anselmo, fingiendo conquistior a su mujer, para no engañarle de verdad; cuando de verdad la concuista y le engaña, entonces no le engaña pues de verdad la conquista, como Anselmo le había cxigido.

Lin el espacio de que aquí disponemos, no obslante, nos limitaremos a estudial textos fragmentarios: quede para más adelante el desarrollo capar de abordar fieciones completas

\section{Análisis de la paradoja}

Ya hemos hablado de la necesidal de una conciencia clana de las novibles dimensiones de la figura. Tan posible es que encontremos paladojas que se ciñan a una frase, como esquemas paradójicos que abarefuen secciones más amplias de texto. Conviene, pues, recordar aqui que si en retórica como en lógica- se debe poder llevar todo razonamiento a un silogismo, en açuélla el silogismo debe poder extenderse". Para la consideración aristotélica, por ejemplo, de una argumentación como la siguiente fácilnente se podrían extlaer paradojas:

Anteayer, en Sevilla, Allonso (juerra se presentó cono adalid de las causas más nobles: criticó el armamentismo, denunció la hipocresía occidental en la Gucra clel Golfo y se proclamó abogado del ecologismo, los marginados, las minorías raciales, los inmigrantes y los jóvenes. Sólo le faltó declararse feminista. ¿Su problemat? Que no es nuevo en esta plaza, y sabemos lo que hizo micntras estuvo en el (jobiemo, como sabemos lo gue hace hoy el Gobierno que él dice apoyar.

(lil Munclo, 2-11-1992)

\section{Fn efecto, recordemos la Retírica':}

Otro [lugar), puesto que no se alaba las mismas cosas abiertamente y para sí, simo que abiertamente se alaba sobre todo lo justo y lo bello, mientras que en privido se desea más bien el propio interés, consiste en intentar sacar de una u otra premisa la

3.- Agude

4.- In "Dos aspectos del lenguaje y dos tipos de afisia», findememes dél lenguaje en colabolación con Morris Halle, Madrid, ('iencia Nueva, 1967. pág. 102: la versión original en inglés ex (le 1956.

5. Foman parte estas notas de un estudio más amplio en curso. en el que se atiende por extenso al as-

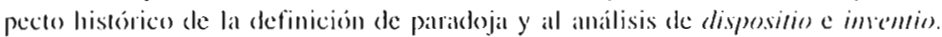

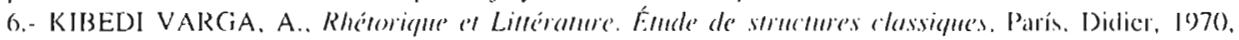
píg. 5\%.

7.- Utilizo la edición de M. Dufour y A. Wartelle, en tres tomos, de la (ool. (iuillaume Budé, 1989). reimpresión (los dos primeros tomos de 1938. el terero de 197.3); para los Tópicos, misma colección. edición de J. Brunschwig. 1967. In Tópicos (104b 19-34), más ampliantente, una partaloja es una kesis contlicliva por enfrentarse a los mís o a los sabios, defendida por algún lilósofo célebre: se recpuiere autorielad y técnica argumentaliva para apoyarla. 


\section{PARA UNA RITTORICA DF I.A PARADOJA}

conclusión opuesta: de los lugares de las paradojas, éste es el más elica\% (1394) al 30$33)$.

Pues ése es el método del anónimo columnista de $1: 1$ Mumdo: inferir de unas declaraciones realizalas por Allonso (iuerra ya al margen del gobierno la contradicción con su comportamiento público mientras estuvo en é. No hace falta decir que la concepción aristotélica presupone un marco argumentativo y dialógico, y que, en consecuencia, resulta mucho más generosa que aquélla a que nos ha acostumbrado la repetición de las definiciones, mucho más formalistas, de Crevier o Fontanier.

La extensión del escfuema paradójico viene determinada, entre otras cosas, por el género (liscursivo a que el texto pertenezal y por si argumenta, expone, o narra. Pero, como figura de pensamiento que es, no tiene por qué ceñirse al ámbito de la frase. Y tanto en este último calso como en los extensos, quien se sirve de palladojas, lo hace a propósito de algo y contra alguien, por lo que el análisis de cada muestra de esta ligura obliga a representarse el drama cntero sirvámonos de la metáfora de Tesnière para la onación- de la comunicación: dos interlocutores que enfrentan sus argumentos a propósito de un discurso seceial cue les preexiste. Fin el ejemplo de l:l Mundo, el columnista apunta como contrario, ya que no a la personla empírica de Allonso (iueral, a su discurso en tanto que previamente conocido, con el fin de volverlo contra él mismo.

a) Argumentación: voces en la paradeja

Así que, auncue a veces en el texto paradójico oigamos que quien habla discute consigo mismo, en ocasiones percibimos el eco de una voz ajena y contraria:

Resulta paradójico que, en el mundo democrático, la incertidumbre respecto de la figura del líder iraquí haya desaparecido precisamente por culpa de una catatástrofe ecológica en el (jolfo provocada por él y no, por cjemplo, por su llamamiento al terrorismo.

(SCHWARTZ, lernando, «Robín de los bosques», El País, 2-II-1991)

Sin duda, ni F. Schwark experimentaba incertidumbre alguna respecto de Sadam llusein, ni el (lerrame de cruelo en el Golfo reviste para clisiparla en su opinión la misma enticlad que el llamamiento al terrorismo. Precisamente él se hace cargo de esa opinión ajena para llamar la atención sobre su carácter contradictorio. Pero hay también cassos conto éste:

«El placer de los sentidos se experimentó muy pronto en todo el cuerpo, y yal no fue solamente el fruto prohibido, cue placía a la vista y al gusto. Adán y Liva realizaron el uno con el otro una tentativa hatro más peligrosa que todas las demás sensibles y, obligados a pensal en ello nosotros mismos, preciso es que de ello desviemos nuestro pensamientom. Me imagino a los obispos reunidos en la Capilla Sixtina en pleno concilio del amor, tratando de no perder los nervios al pensar sin pensarr en la peligrosal tentatival de Adán y Eva, rodeados para colmo de los frescos de Miguel Angel Fn verdacl, hastia que no se frecuenta a los padres de la lglesia no se sabe lo que es realmente pornografia .

(SAVATLR, Fernando, "lil concilio del amor», Impertincencias y desafios, Madrid, Legasa, 1981) 
La expresión «peligrosa tentativa de Adán y Liva» podría ser dicha seriamente por Bossuet, a (quien pertenece la cita que abre el ejemplo, y, en todo caso, por los obispos que se hacen eco (le sus doctrinas, pero no por quien las califica de epornografía». Surge así la ironía complementaria de la paradoja - al servirse el que habla de una expresión ajena, y, esta vez, literalmente ajena. Se puede explicar el problema de la plualidad de voces en el marco de la "teoría polifónica de la enunciación» de Oswald Ducrot, quien ha aplicado a enunciados sueltos la teoría que Bajtín había concebido con un alcance más generals.

Poclemos, pues, afirmar que es propio de la paradoja, en tanto que argumentación condensada, que el locutor - el "yo»" del (liscurso, que no siempre cosincide con el empírico tome a su cargo) una vor contraria (de un uenunciador» en términos de Ducrot) para refutarIa.

Por otra parte, en tanto gue la paradoja recurre a la contradicción, y en tanto que el pensamiento lógico luye de ella, la paradoja supone siempre un énfasis. La mayoría de los casos examinados con las palabras «paráadoja», "paradójico», "paradójicamente», ocurren casi siempre, $y$ no debe ser casual, a principio o final de párrafo, y aun de texio, que son posiciones de realce; los ejemplos que prescinden de tales signos metalingüísticos son más libres, sin ducla porque ellos mismos muestran su propio relieve.

Si nos trasladamos al anćlisis del significado textual de Halliday y Hasan", veremos que se relaciona el enfogue argumentative con el componente que (lenominan interpersonal, y que corresponde al "tenor del discurso», aspecto de la situación textual que tiene que ver con quićnes participan en el acto de comunicación. Pero otro aspecto del significaldo era el lógico, para el cual vale la rellexión cue lleva descle Vico" hasta Perelman: la paradoja separa lo cue a primera visla parecía unido, procede mediante disociación de nociones; nociones podemos añadir- gue pertenecen a los lugares comunes de la cultura, (fue por ello mismo merecen ser dislocados para abrir camino a convicciones nuevas. Fen el primer texto citado, F. Schwartz. atacaba lo prolongado de la incerticlumbre acerca de Sadam Ilusein y la mayor precoupación oecidental por el medio ambiente cue por la vida liunana, haciendo ver: a) (pue se había llegado tarde a una comprensión correcta del presidente iracuí; y b) (jue había bases mejores en qué asentarla que la calástrofe ecológica. I a paradoja resulta ser así, lanto como un arma dialéctica, un procedimiento de análisis, si es que analizar supone disolver, y no sólo en el lenguaje periodístico, político...

8.- I)UCR()T, ()swald, l.e dire el le dir. Parris, Minuit, 1984, en particular el cappitulo VIII. Redactadas ya estas líneas, teo el muy interesante antículo de I uis Beltán "I a enunciación narrativa: el natrador y" la vo\% (lual», en el primer número de tropelias. Supongo que su distinción entre locutor y sujeto cognilivo - si no la entiendo mal--... sería cle aplicación aquí.

Advierto que haré abstracción del hecho de que en la mayoria de mis ejemplos haya discurso referido.

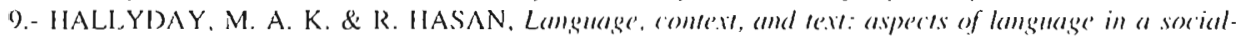
semionic perspertive. ()xford University Press, 1989, págs. 16-23, distinguen tres componentes malyores: el ideacional, que tiene que ver acon la función del lenguaje de ser acerca de algo», subdividide) en una parte de representación de la experiencia (experiencial) y otra de relaciones lógicas yue sólo indirectatmente derivan de ésta: el interpersonal, que concierne a su función social, con particular mención del uángulo del hablante» (algo así como la perspectival enunciativa); y el textual, que se refiere a los medios de colsesión.

10.- Vico, en el apartado "De sententiis, vulgo (lel ben parlare in concetti" de sus Instimziomi Oranoric, distingue dos especies de conceptos, la paradoja y el símbolo: éste presupone la ignorancia del anditorio. aquélla el error. Uso la edición de Opere', vol. VII, Vápoles, 1865. 
b) Mostrar y decir

Se habrá observado que venimos citando ejemplos en los que, mediante la palabra "paradoja», se atirma expresamente que nos encontramos ante un hecho de lal chaliclacl, mientras que otros prescinden de tal mención: se supone que estos últimos muestran bastante, por sí mismos, su forma paradójica. Lllo nos lleval a recordar una articulación, centre lo (jue se dice y lo que se muestra, de amplia tradición en la teoría anglosajona de la narración descle llenry James (showing frente a telling). y en la lingiística (Gardiner, 1932) y la filosofía del lenguaje, asimismo inglesas, sobre todo a partir de Iudwig Wittgenstein.

Fn el Trackarus". de 1922, afirma el lilósolo vienés: "la proposición muestra su senti(lo. La proposición, si es verdadera, muestra cómo están las cosas. Y dice eque las cosas están así.» (\$4.022). Señala como central este contraste $F$. Récanati ${ }^{12}$, quien ha recordado la muy interesante - y olvidada- The Therory of Speerh and Language, de Alan Gardiner, que en sus $\$ \$ 41,52$ y 60 ha dibujalo un contraste equiparable al de Wittgenstein, pero directamente aplicable a lat teoría del lenguaje: palabras y frases describen intencionalmente su referencia en el discurso, pero además «implican»-como armónicos otras informaciones, y esta implicación puede a veces hacerse explícita: «il y a aussi les mots prélixés on alfixés ayant une forme phrastique et montrant les activités du locuteur ou de l'auditeur par rapport à une phrase particulière, par excmple lipargnez-moi. JE VOUS PRIL»"'. Se puede, pues, considerar el uso de expresiones metalingiústicas como "paradojà como manifestación del par «mostrar/decir» -o «implicar/lescribir»-; consecuencia, a su vez, del hecho de que el discurso es, tanto como un medio de referirse al mundo, un hecho en sí y parte. por consiguiente, de éste.

Diferenciaremos, pues, entre:

(1) IAfirmo clue $X$ es una paradoja

(2) |Afirmo parááójicamente que $\mid X$

donde el verbo «afirmo» entre corchetes supone un mero recurso para expresar el carácter de afirmación - la fucrza «ilocucionaria», si se quiere- que ambas frases revisten. «X», en los dos calsos, designa el cnunciado del que se puede alirmar que es paradójico: recuérdense, como cjemplos, el de F. Schwartz y el de Savater, antes discutidos. Fn (1), el locutor advicrte metalinguísticamente al destinatario del mensaje de la cualidad del hecho referidio por el cnunciado; en (2) la estructura de éste debe resultar bastante llamativa de por sí para mostrar su propia naturaleza.

Surge aquí una cuestión: iqué es lo que un enunciado puede mostrar? La misma forma de la alirmación muestra eso, a saber: que es una alirmación, y, a su ve\%, ese mostrar inclica la intención de quien ha hablado, de su acto de enunciación. Pero entonces, una de las cosals que un cnunciado muestra es su carácter figurado, porque éste forma parte de su constitución como tal enunciado y muestra una intención expresiva, "una modalidad cnunciativa imagina-

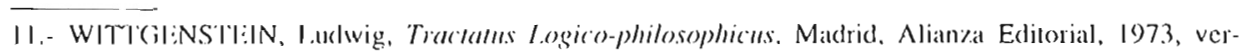
sión española de E. Tierno Calván.

12.- RÉC.ANATI, Fançois, La Mamsparencia y la emmeiación. Buenos Aires, Hachene, 1981, la ed. francesa es de 1979.

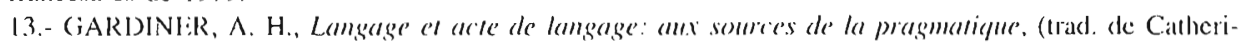
ne Douay), Lille, Presses Universitaires, 1989. Es fácil ver en esta doctrina una preformulación de la teoría de los actos de habla de Austin y Searte respecto de los performativos. 
ria» ${ }^{1 \cdot 4}$ por parte del hablante. Ésta se situaría en el mismo plano que el sentido denotativo, con la advertencia de que la apartente primacía de éste últimes se debe a circunstancias de muestra cultura: "Mais cette primatuté n'est pas inscrite dans le système de la langue qui per-

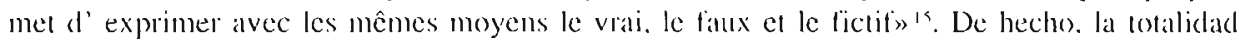
del lenguaje constituye una figuración del mundo's ${ }^{\text {. }}$ que admite múltiples modalidades entre las cuales se da una relación parafrástica: lo que las figuras muestran se puede parafrasear. aurque la partátrassis no llegará nunca a agotar lo mostraclo por la figura en sí.

la conchusión es cue, recuperando la amplitud de la concepción aristotélical, y luego de Vico y (iracián. es preciso no disociar el análisis de los enunciados que muestran su configuración paradójica de acpuellos otros marcaalos metalingüísticamente. Unos y otros constituyen casos, articulades según el contraste entre mostrat y decir, del mismo esquema argumentativo paradóójico.

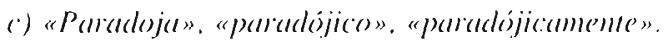

Nos hemos referido a estas palabras como a signos que alertan a quicn lee o escuchal a propósito del enunciado en el cual se insertan. Fil contexto se va modificando según avanzal la lectura en virtud de la linealidad del discurso-, pero la estructura de la memoria no es lineal, por to que esals palabras, cuando aparecen, forman contexto para el enunciado a que acompañan, y después de la lectura quedan indisolublemente unidas como predicación metalinguiística a la predicación básical a la que se aplican.

Los diecionarios de la R.A. F. y de Marría Moliner vienen a coincidir en la atribución de significados: a) idea opuesta a la que se tiene por común o general; b) aserción absurda con apariencias de razonable; c) figura de pensamiento que consiste en emplear expresiones que envuelven contradicción (resuelta en un pensamiento más profundo, añade Marrít Moliner). ral significaldo «al» es el único que registran el Diccionario de Autoridade's yel cle Covarrubias. Se trata, para el español, de un cultismo procedente del griego cuye primer testimonio sitúa Corominas en el Diálogo de la lengua.

Fn realiclad, los tres valores signilicatives que recogen los actuales diccionarios condensaln una historia de más de dos milenios y expresan suficientemente la natturalezal de la palabria. Li significado "a» parece conservar el uso idiomático griego del (pue partió Aristóteles; el absurck (lel signilicade «b) se sigue probablenente de la oposición a la opinión común mencionada en «il»; y en cuanto a «c» se reduce a la definición retórica corriente, no más antigua de Crevier", pero generalizalda a partir de Fontanier. Fil tránsito de "al» a "c» no es ajeno al alsentamiento del formalismo en la tradición retórica: no es nadal difícil confundir la

14.- De hecho, se ha procedido ya en ocasiones descle una concepeción parecida a la alquí esbozada: en su tipología de sonctos clísicos, entiende (i. Berrio por usimil» no la existencia de metáforas ocasionales sino una modalidad expresiva referida a la "globalidad textual integra»: GARCíA BERRIO). Antonio, "L.ingiístical del texto y texto lírico». REL. cnero-junio, 1978, píg. 35.

15. TAMBA-MEC\%, lrène, l.e sens figuré, París, Pll: I981, pág. 199.

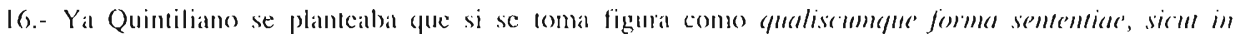

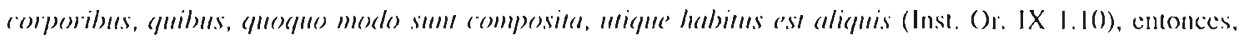
no hay hablar yue no sca figuraclo (ed. de J. (ousin en sicte tomos, alparrecida entre 1975 y 1980) en la Col. (juillaume Budé).

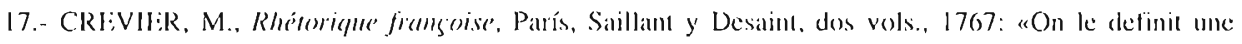
lïgure qui allïme ou nie l'une même chose les deux contraires» (1. II, pág. 255). 
opinión general con lo razonable, y lo que a ella se opone con lo contradictorio (pero) con ello se salta de lo social e histórico a lo lógico; cfir. el ejemplo de paradoja de Covarruhias: "lue es el globo de la tierra el que anda a la reclondia).

Lin rigor, de lo que es nombre «paradoja» es de una entidad lógica y retóricia con la que los hablantes analizan y argumentan, y, alesde luege, existe. adcmás de en español, por lo menos en italiano, francés, inglés y alemán, siempre con una forma fónica muy semejante y próxima al la fuente griega, y con un valor semántico similar. Liso parece lo propio de las terminologías, cuyos significados use conocen en la medida en (pue se conocen las ciencias y las técnicas a las que corresponden, y no en la medida cn que se conoce la lengua» Is. De ahí yue, para una óptica estructuralista en sentido estricto. supongo que "paradeja» no debería contar como término metalinguístico, pero sí para un análisis lógico, como el de $\mathrm{H}$. Reichentbach". para el cual "paradoja» liguraría como término metalingüístico semántico — junto a "tautologià", "contradicción», etc. auncpue tiene también su lacko pragnático, en tanto que «sorprendente».

De hecho, en su uso actual, esta familia de palabras parece expresar simultáneamente recordando una ve\% más el análisis en niveles de significado de Halliday y Ilasan dos vatlores:

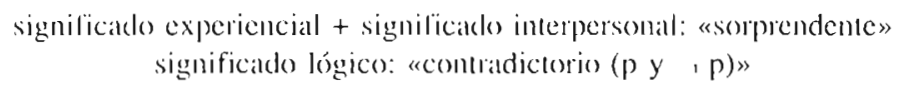

Donde «p» $y$ «- $p$ p son lugares vacíos que deberá llenar la proposición expresiala por el contexto de "paradoja» o de sus correspondientes adjetivo o adverbio. Que se trate de «pa-

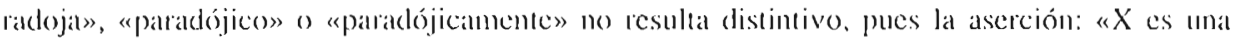
paradojà». se expresa por medio de cualepuicr categoría glamatical -sustantivo, adjetivon 0 aclverbio (jue pueda servir de base a una predicación:

Fin el seno de la (Jnión del Magreb Árabe (UMA) las situaciones son, cuando menos, paradójicas. Primera paradoja: el coronel Galddafi, siempre dispuesto a abrazalr las calusals nacionalistats y a denunciar el umperialismo norteamericano», ha daclo mucstaas hasta el momento de una considerable moderación (prosigue dando razones para esa moderación].

(BAI:1^. Paul, "Fiebre en el Magleb», lil País, I6-II-1991)

I.o) curioso del caso es que el movimiento pacifista no parece tener claros sus objectvos. Organiza manifestaciones ante las bases norteamericants y británicals, denuncia a las empresas que vendieron material bélico al régimen de Sadan Husein, pero se olvida de lo que realmente está haciendo el Gobierno de Bomn. Porque, paratlójicamente, lo cierto es que, aparte de no enviar tropas, la contribución de Bonn al esfuerzo bélico aliado es de primera magnitud.

(lil País, 29-1-199)1)

Lil ejemplo con adverbio se puede parafrascalr como:

fatirmo (juel es paradójico que sea cierto que ...

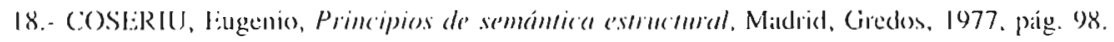

19.- RI:ICHENBA(H. Mans, Symbolic I.ogic. Nueva York, Macmillan, 1966, págs. 344-354 (Ia primera edición es (le 1947). 
Por consiguicnte, el significado adverbial se aplica a la afirmación enunciada en este caso, la certeza de que el Gobierno de Bonn contribuye a la guerra y la predicación se establece como en los orros casos.

Fixaminemos alsora un nuevo ejemplo:

F.l ministro español de Interior, José Luis Concuera, defendió en la conferencia una posición común a diversos países occidentales asistentes, segín lia cual el problema de la emigración del Este debe solucionarse, funclamentalmente, mediante la «cooperación política y económica» con las naciones exportadorals de mano de obra. "l a situación de los países occidentales no permite el desarrollo de una emigración de carácter permanente», señaló. Corcuera destacó el paradójico incremento registrado en España de solicitudes de refugio o asilo por parte de ciudadanos de países del Fste tras la liberalización de sus regímenes

(t.l País, 2.5-1-1991)

Aplicando la interpretación de "paradójico» como «p y $\neg p$ »:

«p»: liberalización política -> (permanencia en el propio país)

« p»: liberalización polítical -> incremento de solicitudes de asilo, contratio a la permancencia esperable

La paradoja consiste en enunciar un juicio y su negación, pero con la peculiaridad de que la consecuencia del juicio no es explícita: a la vista (lel «incremento de solicitucles» y de un conocimiento extralingiístico, ideológico, el lector infiere que ha sucedido algo que niega lo esperable, lo esperable desde la óptica del locutor, naturalmente. Pero la interpretación propucsta no valkiría menos para un cnunciado como: "Corcuera destacó el incremento registraclo en España de solicitudes de refugio o asilo por parte de ciudadaunos de países del Fste tras la libcralización de sus regímenes» (perfectamente aceptable sin «paradójico»). ¿Qué aporta, cntonces, la presencia de este adjetivo? Justamente, es él el que añade a la frase un supuesto formulable aproximadamente como:

"|incremento de solicitudes... en ve\% del incremento de la permanencia ch sus países, que era lo coherente y esperable, supuesta la liberalización...»

Ls decir, que igual que: iquién ha venido? presupone necesariamente la venida de alguien, la aserción de que «X es paradójico» presupone, con igual necesidad, que « $\neg \mathrm{p} X$ es coherente». Presuposición que se compone de dos miembros: a) la negación de lo afirmado como paradójico: "en ve\% del incremento de la permanencia...»; b) la justificación de lal negación mediante el primer juicio: «liberalización» -> «permanencia». Justamente, este juicio es la noción de «sentido común» gue la paradoja clisuelve para resaltar una convicción nucva, y sin dudil es a esie paso al que se relirió Vico en su análisis: la paradoja procede a partir del error en el que el auditorio se encontraba. Nótese que, sin "paradójico», el enunciado seguiría siéndolo, pero de un modo, digámoslo así, desvaído: probablenente, un lector interrogalo al respecto contestaría que estábamos ante un hecho paradójico, pero habría que preguntárselo, no lo apreciaría espontáneamente por sí sólo; he ahí el lado pragmático del término: de subrayado, que convierte una frase (jue pudiera pasar desapercibida en arma dialéclica. Así que la función de "paradójico» recuercla a la de los llamados "activadores negativos»"

20.- BOSQU1:, Ignacio, l.a megoción e'n éspañol, Madrid, Cátedra, 1980, pág. 26. 
respecto de la negación: disparal el esquema de la contradicción; y con ese nombre. "activatdores», designarcmos desde ahora a los términos metalingiústicos.

Volvamos ahora a otros cjemplos cue arriba propusimos. ¿Qué paradoja haly en cace el coronel Gaddafi dicra muestras de moderación? (Ota vez es un enunciado "lagunar»" ${ }^{2}$. en el que se cstablece una implicación cuyos -acui clos- últimos pasos no están explícitos:

«nacionalismo y antiimperialismo -> (radicalismo -> apoyo a Saclam Iluscin)»

Lin la medida en que estamos ante un auténtico razonamiento, pero incompleto y tal ve\%. no muy preciso, viene a las mientes la concepción aristotélica de uentimema», el silogismo «rebajado» propio de la retórica. Pues bien, supuesto lal cncadenamicnto, el lector que recuerda "primera paradoja» y que lee "ha dado muestras... de... moderación», presupone algo así como «moderación que niega lo esperable: el apoyo a Sadam Iluscin»; pero esperable de acuerdo con la implicación que el locutor supone hubiera inferido cualquicra: justamente to que el locutor hace es negarlia.

Semejante análisis admite el otro ejemplo. La frase «aparte de no conviar tropas» alpela al argumento implícito «p»: "contribuir a la gucria implica enviar tropas», para afirmar "p»: «Bonn contribuye a la guerra sin enviar tropas». Como en el caso anterior, un solveentendido permite condensar toda una cadena argumentativa, que el locutor selecciona -de entre las posibles proporcionadas por una «tópica social»- como hipotético argumento contrario al suye propio, para luego disolverlo mediante una negación —en este ejemplo, explícita , que conduce a un conocimiento de la realidad gue él asume cono más preciso.

F.l esquema a que se ajustan los textos citados, es, pues, el mismo, aunque sea diversa la complejictad de aquellos, diversidad, que, de lodos modos, se explica sin problemas. Fin efecto, en nuestla cultura, y hablando de los países del Fiste, "liberalización» reviste un significado inequívoco y suficiente para establecer la paradoja. Por el contrario. se precisa una caracterización política del coronel Gaddafi - la frase de participio «siempre dispuesto...» sin la cual nada de sorprendente ni contradictorio revestiria el hecho de su no participación en la guerra. Asimismo, sin el inciso "aparte de no enviar tropas», el senticlo del otro texto variaría sustancialmente.

Ahora bien, ¿estamos en todes los ejemplos- ante conladicciones lógicas? Respecto de ascrciones como «el radicalismo implica apoyo a Sadam Husein», "contribuir a la guerra supone enviar tropass», o "la libertad política debe detener el exilio», hemos hablado de presuposiciones porgue sólo presuponićndolas tiene sentido afirmar gue sus negaciones constituyen parladojas. Ahora bien, la relación entre éslas y los términos que presuponen no es lógica, ni pragmática, sino empírica: no está en juego aquí la relación entre los signos, o entre éstos y sus usuarios, sino la referencia de éstos últimos al mundo extralinguístico. Fil destinalario de los mensajes presupone tales asertos recurriendo a un determinado conocimiento de la historia inmediata y desele su propia pertenencia a una ideología preclominante en el llama(d) mundo occidental ${ }^{22}$. Pues bien, tratándose de formulaciones de este tipo, podemos afirmar

21.- SPEERBL:R, Dan, «Rudincents de métorique cognitive», Pó́tique. 23, 1975, píg. 398.

22.- No se trata de cisa distinción han liecuente entre conocintento lingiústico y' conocimiento del mun(o), porcue lo que aluí estí en juego, más que un conocimiento. es una serie de creencias y valores como: cualquier radicalismo es malo, el nacionalismo tiende al radicalismo, etc., en una palabra, unat icleología. 


\section{I:LRNANDO) ROMO}

con Perelman" que más que de contradicción se trata de incompatibilidad. Les cierto que tenemos la negación de un juicio por otro, pero la negación consiste acjuí en enfrentar un comportamiento político de hecho con el que, según el analista, cualquiera esperaría en función de la historia anterior y el "scentido común»; todo depende, así, de cuestiones contingentes y" de una lógica de lo verosímil, no de causas cstrictamente formales.

Pero hay más: ¿qué es lo realmente afirmado en los ejemplos vistos? Se ha levantado acla de tres hechos, a saber: que el coronel Gaddafi no ha apoyado a Sadam Husein; que la emigración de los países del Fste no ha cesaldo, a pesar del hundimiento de sus regímenes; y que el (iobierno de Bonn apoyaba con todas sus fuerzas al bando aliado, a excepción clel envío de tropas. Lals aseveraciones inversas a tales negaciones no se han afirmado, sólo quedan sugeridas: su autoridad, su estatute discursivo, no resultan, pues, comparables. Ahora bien, ¿.por qué el antiimperialismo debería siempre llevar a la guerra, la gente huir de sus países sólo por causas políticas y no por la miseria, o la ayuda cconómica y logística no constituir una forma direcla de participación bélica? Tal parece que los locutores presuponen como esperables por cualquicra y evidentes de por sí asertos que dislan de ser evidentes y de los cue cualquiera que se (letuviera un momento dudaría razonablemente. En otras palabras, al par que destacan como sorprendentes ciertos hechos, sugieren unos enemigos dialécticos que salben vill a vencer, con lo gue reafirmann su autoridad argumentativa.

\section{(1) P'arculejas mostructess}

Lin ve\% de activadores y presuposición incompatible con lo enunciado de hecho, éstas aliman expresa y sorprendentenente- dos cnunciados incompatibles. Aunque no son en absoluto privativas del lenguaje literario, en él se registran los ejemplos más recordados: no hace falta decir que casis sólo de éstas se ocupan, cuando lo hacen, las retóricals más usuales.

Sin embargo, si nos mantenemos en la concepción amplia cue venimos mancjando, las cosas no son lan sencillas. Pues haly que reconocer que a ejemplos como el de arriba, dedicatdo a Alfonso (inerra. se le puede anteponer una frase comso ues parackójico que...». Veamos otro ejemplo:

Cuando íbamos a la escuela se nos decía reverencialmente que el saber no ocupa lugar. Al cabo de los años vamos descubriende que uno de los lugares menos ocupados por el saber es la escuela. por obra y gracia de las supersticiones contumaces de la Pedagogía, que es una de esas ciencias fantasmas que tanto prestigio cobraron con los años setentia, como la sociología y la psicología y la comunicología, por no hablar del estructuralismo, aquella jerga tan francesa y tan árida cue tenía la virtud de volverlo todo inclescifrable.

(MUÑOZ MOL.INA, Antonio, "La exaltación de la ignorancia», ABC: 22-XII-I988)

El ejemplo tiene la virtud de permitir apreciar bien la transición entre lenguaje literal y figurado, o, dicho de otro modo, cntre paradojas "dichass y "mostradas». Fin efecto, admitiría —como apuntábamos- la anteposición (le algo así como « [es paradójico (juc| uno (le los lugares menos ocupaclos por el saber sea la escuela, por obra y gracia...". Io cual atestigua bastante su cualidad de paradoja. Pero esta cualidad no se pierde sin el añadido, auncue, in-

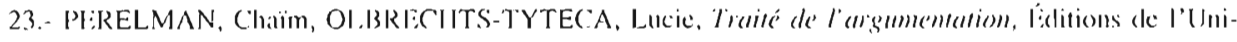
versité de Bruxelles (5.' ed., primera de 1958). 1988. pág. 263. 
dudablemente, la frase «uno de los lugares menos ocupados por el saber es la escucla» exige una justificación contextual - - (jue el autor añade mediante un desarrollo irónico--, sin la cual su propia concisión dejaría al lector sin criterios interpretativos.

¿Qué es lo que separa, entonces, las paradojas mostradas de las dichas? No sólo la concisión de ac|uéllas, (uue, al aproximar términos explícitamente incompatibles, primero, llama la atención sobre la peculiariclad del enunciado en sí, y, segundo, exhibe una particular tensión en la enunciación: cuando la frase paradójica precisa de justificación contextual, necesariamente su intensidad se diluye. Por consiguiente, es necesario que la paradoja se sostenga valga la expresión sola, privalda (le (lesartrollo explicativo alguno, lo que sólo es posible si apela a nociones suficientemente tópicas y consabidas en el ámbito de la cultura:

Fl juego de (Guerra, confesando ahora cosas asombrosas (nada asombra tanto como lo que yai sabramos) es de (loble dirección: publica a su amigo Felipe de vendido a los poderes fácticos o fuerzas armadiss de la Prensa y el dinero, y al mismo tiempo inicia campaña y cruzada para liberar al presidente de esos poderes que le lienen secuestratdo.

(UMBRAI., Francisco, «El secuestraklo», El Mundo, 6-II-1992)

Fil contenido del paréntesis ilustra la línca de argumentación gencral, pero reviste un catrácter de máxima que lo independiza del contexto. Por lo demás, el mecanismo no es diferente al de otros cnunciados examinados: "asombra» presupone «algo nuevo», que es to negado por "ya sabíamos». No hace falta clecir gue hay paradoja: la proximidad contextual entre los términos citados lo muestra; hay referencia, pero exterior al paréntesis.

Y, como prueba supiementatia, acudamos a los ejemples de parcedevisme aportados por Fontanier. Menos dos, todos - y hay más de veinticinco ocupan un solo verso, acompañados de brevísintas explicaciones, porcue versos como: "Pour réparer des ans l'irréparable outrage» o: "Souvent trop d'abondance appannrit la matière»": sin duda se explican solos.

Lin los calsos disculidos en el apartado anterior - acompañados de activadores se establecían implicaciones basalias igualmente en tópicos, o en el "sentido común», pero para contrastarlas con los hechos sorprendentes realmente alimados, con lo cual lo realyado era la referencia extralingiúśstican, (ue obligabal a disolver aquellas implicaciones. Ahora, por el contrario, o no hay tal referencia, o si la hay en la fieción - los personajes y situaciones de Racine, de quien espiga fontanier sus ejemplos siempre se reconoce en el fondo esa tópica social a cue aludimos. De modo que el lenguaje, que resultaba transparente para enviar a los hechos, se vuelve aquí más opaco. Pero, entonces, lo yue separa los dos tipos de paradojas no son lactores puramente lingüísticos, sino aclemás pragmáticos, referenciales, y también sociales, históricos...; si bien, con un denominador común, gue permite reunir unos y otros tipos bajo una misma rúbrica, en la medida en cue todos muestran "lit ccuación oricntada de clos proposiciones desemejantess", una de las dimensiones en que se apoya el senticlo figura(lo.

Nos referiremos ahora en particular a las paraclojas mostradas, esto es: liguradas-, condensadlas o seguidas de justilicación. Facilitará el examen de los diversos tipos registra-

24.- Todos los subrayades son del autor. F(ONTANII:R. Pierre, Lés figures du discours, Palrís, lilammatrion, 1977, pígs. 137-141.

25.- 'ТAMBA-ME(\%, op. cit., pág. 189. 
dos, la discusión de los trabajos de Neal R. Nomick ${ }^{20}$, quien, en el ámbito de la teoría de los «marcos de referencia» (fremes of reference), propuso un análisis de las paradojas en tres mecanismos básicos y un tipo complementario.

Norrick distinguc tres «estrategias»:

la que procede separando marcos de referencia: «We regularly apply this strategy to statements like 'Suc's both right and wrong' to get a consistent interpretation, such as 'Sue is right theoretically and wrong practically'»;

la que procede «promediando (averaging) opuestos»: «when we take a statement like 'It's raining and it's not' to mean 'It's just barely mining', and hence 'It's drizzling'»;

la que procede modificando un término: "We all employ this third strategy to find consistent interpretations for statements like 'Al is thirty-live going on twenty', when we alter the second term to 'acts like he's twenty'».

El autor considera, además, un tipo propio de algunos proverbios e irreductible a los anteriores, cue ilustra mediante: "Nothing is permanemt but change», y cuye paradigma sería la clásica paradoja del "mentiroso», a la que habremos de referimos.

La teoría de Norrick se refiere exclusivamente a las paradojas «mostradas», se apoya en un corpus de "conversación natural», y se orienta hacia el estudio del humor y el juego de palabras. De modo que cabe la observación de que, al prescindir de un marco más amplio, argumentativo, restringe excesivamente sus análisis, que nosotros probaremos a extender a los ejemplos que venimos considerando.

De entrada, homos de matizar una de sus conclusiones: "All the evidence so far suggests that the clash of meanings in the paraloxes themselves must determine which strattegies apply, and not the identity of the speaker and hearer, or context, or topic of discussion" ". Si admitimos en la clase de las paradojas las acompañadas de activadores y que nadie, que yo sepa, se haya referido a ellas, no prueba sino una carencia de la teoría- se comprueba que, a diferencia de las "mostradlas", no se reparten entre las estrategias citadas "with no noticeable differences». Antes bien, muy al contratio, todias proceden separando marcos de referencia. Recordemos, en todas se enfrentaba la expresal aserción de un hecho con una implicación esperable de acuerdo con el «sentido común»; no cabe ahí vartiación en la interpretación de un término, ni mediación alguna, sólo la negación de que, por ejemplo, halya clisminuiclo el número de personas que abandenan los países del Fiste, rechazadal por haber demestrade ser, auncue esperable, falsa, en vista de cue ese número crece a pesalr de la liberalización política de esos países. Creo que esta táctical argumentatival corresponde a la aludicla separación de marcos de referencia: noción tópica frente a hecho alimato por el locutor. Alora bien, ¿qué significa "mareos de referencia»? Yal vemos (pue, al menos en el primer tipo comentado, se taata de dos realidades de estatuto teórico dispar: implicación frente a aserción; y que estia táctica de resolución no es independiente de tres hechos: la existencia de referencia ella define la diferencia entre implicación y alserción ; el contexto general argumentativo y la afirmación de la autoridad argumentativa del locutor.

26.- NORRIC:K, Neal R., "From wit 10 comedy: Bisociation and intertextlality". Se'miotica 67, 1/2, 1987: "How Palladox Mealls". Poelica Todeỵ 10: 3. I989, pígs. 5.53-5.58.

27.- ()p. cil., págs. 557-5.58. 


\section{PARA INNA RFTÓRICA DE LA PARADOJA}

Donde sí parece cumplirse la presencia indistinta de los tres procedimientos alislados por Norrick es en las paradojas mostradas:

La 12:" marcha a Torejón, prevista para el próximo (lomingo, "exigirá el uso civil» de la base madrileña, según anmeió ayer Manuel (jari, porlavo\% de la Comisión Anti-()TAN, ma de las 43 organizaciones convoximtes del acto. Gari justificó la celebración de la marcha, las la salicla de los áltimos cazas $\Gamma$-lo de Torrejón, el martes. subrayando que "los americanos se van pero se quedan», ya que contimuarán en Rola (Cádi\%) y Morón (Scvilla) y podrán regresalr a Madrid «en cualquier momento».

(I:I Pais. 27-III-1092)

Un caso como éste" enta, sin duda, en la táctica de "promediar" opuestos, con la peculiaridad de que tal mediación no se deja a cargo del lector, sino que el loculor que refiere el (liscurso de un enunciaclor ajeno, añale a la paradoja «se van pero se puedarm la comespondiente explicación del enunciador: irse pero quedarse supone abandonar unas basces pero no otras, y por consiguiente, no irse del todo. ¿En qué consiste, en realidad, este tipo? Lil todos los ejemplos registrados tenemos antónimos y parece indilerente bajo cuál de sus formas posibles: los hay no graduables, es decir, contradictorios (el «pensar sin pensar» de los obispos de Savater: irse/puedarse), graduables (el incremento o disminución de los yue huyen de sus países), o inversos". No encontrando el lector un hiperónimo claro que abarque y concilic los dos términos enfrentados, "promediar», en realiclad, es construir un tercer término que suponga la modificación parcial del que se acepte como positivo. A veces la lengua ofiece al lector una pieza léxica (jue cubre csal necesidad: en el ejemplo de Norrick, "llover y no llover» se resuclve mediante «lloviznar»; cuando no, «pensar sin pensar» será un molo (le pensar (pornográfico, morboso, ekc); «irse y quedarse» será un irse parcial, un modo de quedarse. Así que, lo que aquí tenemos es la utilización argumentaliva de un recurso semántico de estructuración del léxico.

Fil tercer lipo de Norrick recurría, para la imerpretación, a modificar uno de los términos, lo que puede hacerse mediante el sentido ligurato:

In la clásica novela de Arthur Koestler Darkness and Noon, que lata de los procesos de Moscú de los años treinta, hay un momento crucial cuando el principal acusado, Rubashov... está ya a punto de rendirse, auncpue aparenta seguir resistiéndose. Ivanov, el interrogador del NKVD... le propone a Rubashov que comprenda su propia siluación en los siguientes términos. Por supuesto, nadie cree de verdad observa Ivanov refiriéndose a los cúrculos internos del partido- el que Rubashov, un antiguo revolucionario, sea en realidad un traidor. Pero la revolución había sulrido terribles reveses y necesitaba víctimas propiciatorias. Si Rubashov asume la desagradiable tarea de convertirse precisamente en esa víctima propicialoria, éste será su último servicio al partido. Después de la victoria, los analistas de la revolución reconocerán su gran sacrificio.

(HIELI.ER, Agnes, «El último servicio de Stalin al partido», lil País, 20-1-1992)

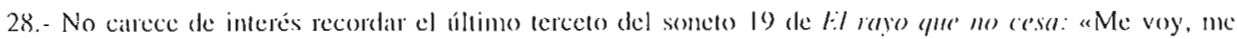
voy, me voy, pero me quedo./pero me voy, desierto y sin arena:/adiós, amor, adiós, hasta la muerte». El escuemar la figura - es idéntico, y las diferencials se explican por ser un soneto, por el contexto, ete. 29.- I.YONS, John, Semmímica, Barcelona, Teide (1rad. de Ramón Cerdá), 1980 (la éd. original inglesal es de 1977), págs. 254-26.3. 


\section{I:ERNANDO) ROM()}

L al paradoja contenida en el argumento de lvanov contra Rubashov es evidente: el último servicio del revolucionario al partido consistirá en convertirse en traidor; y la resolución, indicada por acpuél, también es clara: el segundo término de la contradicción, "traiclor», modifica su semántica para convertirse metafóricamente a los ojos de interrogador e interrogado en «víctima propiciatoria». Así, la incompantibilidad desaparece, ya que se será simultáneainente traiclor para unos y víctima en el fuero interno para otros. El recurso a la metálora constituye, pues, açuí la clave interpretatival, con la única particularidad de que, lo cque en los cjemplos de Norrick se construye mediante implicaciones, ayuí es propuesto explícitamente por el entunciador como parte del propio argumento.

Sintetizando lo expuesto, reconocemos en las paradojas mostradas los tres primeros tipos de Norrick, aunque puntualizando que sus estrategias consisten en la utilización con fines argumentativos de recursos semánticos habituales. Pero aquéllas no son independientes dél contexto y la referencia, y con más amplitud, del mecanismo general de la semiosis: construir una interpretación verosímil en el cuadro de un conocimiento del mundo y de la pertenencia a una cultura es lo que fuerzal al destinatario del mensaje a separar "marcos de referencia», promediar opuestos o modificar el sentide de un término. Ahora bien, como hemos comprobado, en el calso de las paradojas acompañadas de activadores, la primera de las estrategias de Norrick es la única que achúa.

\section{(e) l:I (irculo vicioso}

Como recordarenos, había un último tipo, ejemplificado por enunciados como unada es permanente sino el cambio». de muy dudosa - acaso imposible resolución, que exhiben en su estructura ese tipo de paradojas que tanto quehacer ha dado a lógicos y filósofos en la Grecia clásical, la Edad Media y el presente siglo, las tres grandes épocas de la reflexión teórica sobre estos problemas.

Las paraclojas semánticas son muy numerosas, pero las más conocidass son:

Epiménides, fue es cretense, dice que los cretenses mienten siempre; entonces i,dice la verdacl o miente? su. Como es cretense y mentiroso, su aserción debe ser falsa, pero entonces, los cretenses no mienten siempre. y él no es cretense; pero. en ese caso, ha dicho la verdiad, y entonces...

o en la versión condensada: isi yo digo que miento, digo la verdad o miento? Si (ligo lat verdad, es mentira (que miento; si miento, digo la verdad, pero entonces no miento, y es mentira lo que digo...

Nos interesal recordar los mecanismos internos de las paradojas «sui-lalsilicadorals»: son

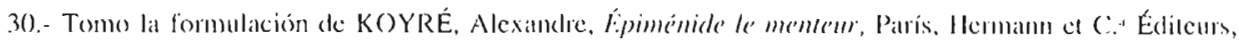
1947. Lste argumento ha conocido otras versiones, (pue ayudan a penetrar en su estructura lógica:

- La versión fomalizada de l.ukasievic\%: sea "p" el enunciado ueste enunciado es falso». Si es falso. lo verdadero es la negación de lo (pue dice, y por tanto, si up" es fialso, "p" es verdadero; pero si "p» es verdad, será verdadero lo (jue diec, y entonces, si up" es verdadero, "p» es falso;

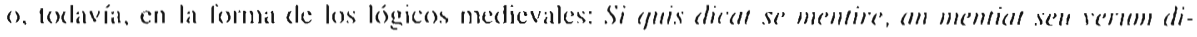
(')1!' 


\section{PARA UNA RFITORICA DLE LA PARADOJA}

auto-referenciales, predican su propia falsedad y engendran un razonamiento indefinido que va de lo verdadero a lo falso para volver a lo verdadero, y así sin límite".

Pues bien, si cabe clasificar con Godar-Wendling las paradojas semánticas en emparentadas directa $\mathrm{c}$ indirectamente con la del mentiroso, y éstas últimas en paradojas de totalidades ilegítimas y de violación de leyes internas, enunciados como los cilados por Norrick entrarían en el áltimo grupo. Lin cfecto, la contradicción interna entre el conteniclo semántico del sujeto («nada sino el cambio») y el predicado ("es permanente») provoca que estos enumciados constituyan una violación de la ley - una única ley fundamental que cllos mismos pretenden imponer". (iraffiti como el famoso "prohibido prohibir» entran sin dificultad en esta clase. Descle un punto de vista retórico, estas frases presentan a veces la apariencia concisa e indiscutible de las máximas que precenden expresar una sabiduría proverbial, y si se cilan, es lanto en apoyo de la propia argumentación como para demostrar la agudeza de quien las formula. Y (esele un punto de vista gramatical con frecuencia se apoyan en la combinación de formas nominales y verbales de la misma base léxica.

Naturalmente, lógica y retórica no se superponen y podemos encontrar casos que guarden una semejanza lomal con los anteriores, pero de dudosa adscripción a este tipo:

Felipe Gonzále\%: "Cuando los comuptos dicen que hay comupción es que se están lapatido) |titulatu|

lelipe Gonzále\% (lijo sentir una repugnancia casi ilimitada ante quienes en ve\% de defender el nombre de nuestro país hacen declaraciones de denuncia de la cortupción, "y yo sé (que son cormplos». "Cuando los corruptos dicen que hay corrupeción es que se están tapando. Lis una inlamia decir que hay una corrupción generalizacla, aungue a veces lo digan acpuéllos (que han paséado un dictador bajo palio», añadió.

(Diario de Cindiz, 2()-I-1992)

Fin el cuerpo del texto resultaba claro gue ese "los comoptos» genérico apuntaba claratmente a cuantos, fuera del PSOF, hablaron de corrupeión, pero en el litular la liase reviste ese estilo lapidario propio de proverbios, máximas y reframes, obligados a prever un cierre textual para lograr el carácter memorable que les es propio ". Lis claro, además, que el juego etimológico «corruptos/corrupción» recuerda al ćrculo vicioso. Sin (ludia, podría haber en la frase en cuestión una cierta reflexividad, puesto gue, demunciando los comuptos la corrupción, a primera vista quedarían ellos incluidos en la demuncia, lo que contradice la noción implícita «de sentido común» de que el (lelincuente no se autoinculpas pero el segundo miembro aclara que se trata de una táctica hipócrila (otra vez el «decir/hacer» aristotélico). Por otra parte, no se produce acjuí esce vaivén indefinido de lo verdadero a lo falso propio (le los ejemplos más conspicuos del círculo vicioso. De modo que hay en la declaración de Gonzále\% paradeja. pero faltan la reflexividad de la liase sobre sí misma y la progresión indefinida de lo verdadero a lo falso y viceversa, que son las dos propiedades características

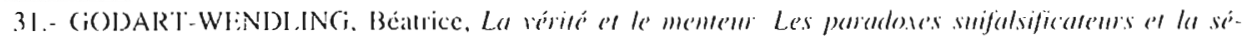
mantiguc des lamgne's mamurelles, París, C.N.R.S., 1990, pág. 32 y sigs.

32.- (Op. cil. pág. 28.

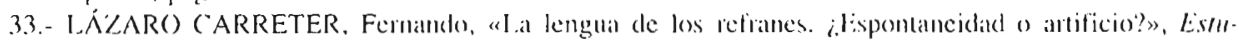

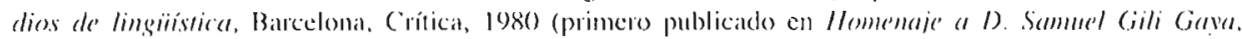
Barcelona, Vox, 1979), pág. 222. 
del lipo aludido. I o que no quita a la frase, dicho sea de paso, su elïarial dialéctica, que se beneficia de la semejanza, de un lado, con los proverbios, de otre con el círculo vicioso.

La cuestión ahora es: aagota la suma de los lipos anteriores las posibilidades ale aparición de paradojas?! Fxaminemos un nuevo ejemplo:

L.legado el caso, el Supremo Jue\% me permitirá (jue me reponga de la impresión que su cxistencia me habrá producido, me mostrará la labla de sus mandamientos y me (liráa:

-loú mismo. (Fspero que me diga «lu mateix».)

¿Mc criticals?

- I cejos de mí hal pretensión. Si no he cejédo en vos ha sido precisannente para no tener que criticaros. Bueno, para no ener que criticar lo gue decian de vos vuestros administradores terrenales. Alora que sé que existís, me inclino a pensar que le dejasteis el sexo al diablo para (que hubiese un poco de juego, como si le lubbieseis dado una ventaja de dos hoyos o de lo carambolas.

(MARQUĹS, Josep). Vicent, «Sólo para católicos». lil Pais sc'manal)

La paradoja consiste en que se dialogue con apuél cuya existencia se afirma no erece. Aquí se juega con ona forma de presuposición, la existencial, establecicla por liege en su conociele artículo Sobre semblo y referemeia: "cuando se alima algo se sobrecntiende siempre como supuesto (que el nombre propio usado, simple o compuesto, liene un significado»". Así que el empleo de "vos» supone la conviceión de que hay alguien a quien así se designa, y eso es tan indiscutible que el autor precisamente juega con ello: "si no he crédo en vos..." Parecido mecanismo se puede comprobar en este olro ejemplo, que citamos para demostral que el lipo vale no sólo para enunciados de repereusión, digamos, teológica:

Li exabrupto del ministro Corcuera contra los intelectuales, lejos de ser agua pasada, deja en el aire interesantes preguntas: ¿qué es un intelectual?, ¿para qué sirve?, ¿es bueno o malo ser intelectual?' Y yendo más lejos: ¿existen los intelectuales, dado gue casi nadie se presenta así y no vienen en las páginas amarillas:? ...

lodo está bastante claro. Si ante un problemal no sabes resolverlo eres un ignorante. Si sabes resolverlo, eres un experto. Si sabes explicar por qué lo resuclves así, eres un cientílico. Bl intelectual es una persona que pregunta por qué le plantean ese problema y no otro, por qué se lo plantean así o cuáles son los verdaderos problemas. Si quien ha puesto el problema es el poder - cuya misión parece no ser tanto resolver los problemas como controlar qué problemas se plantean y cuáles no-, el intelectual se convierte en intelectual comprometido. Pero no lo sabrá seguro hasta que el poder no le insulte. Ciracias al señor Corcucra somos efectivamente intelectuales.

(MARQUÉS, Josep-Vicent, «Ser o no ser intelectual», Fil Pais, 16-XI-1901)

Pues bien, creo que el tipo yue comentamos está emparentado con las paradojas de violación de leyes internas arriba tratadas, ampue, claro está, con dilerencias: aquí la ley quebrantada, no siendo establecida por el cnunciado paradójico, no varía con él, sino yue es la

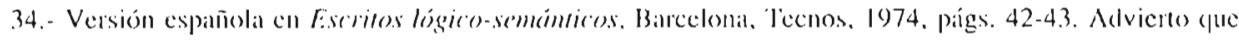

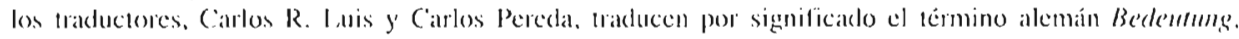
que otras tadfucciones vierten por referencia. 
misma para toclos: se trata sicmpre de csa presuposición existencial del nombre, "propio» en la terminología de firege, nombie sin más, para nosofros, con tal de gue se concuentre en un acto de habla de intención designativa o referencial. Nótese, por otra parle. que este lipo de paradojas no se deja reducir a ninguno de los anteriores, por lo que poelemos considerarlo como lipo específicos.

Diremos, pues, que aceptamos con Norrick la existencia de un tipo de paradojas que se relaciona con las clásicas de la lógica y la filosofía del lenguaje; puntualizamos gue se trata de paraklojas de violacion de leyes intemas; y añadimos un subtipo, emparentado con éste, que juega con la presuposición existencial - en el sentido de liege- del nombre.

\section{f) Los átiles de la contradicción}

Un repaso a nuestro corpus nos permitirá una ojeala a los útiles de que se sirve el esquema de la paradoja y disculir algunos aspectos que merecen más atención:

a) activadores: "paradoja» y sus derivados,

b) términos lingiiísticos,

c) la referencia,

d) la presuposición existencial,

e) el tópico (en sentido) aristotélico): decir/hacer.

la presencia (le los activadores se la siempre en el lenguaje argumentativo -auncue también se registren en éste paradojas mostradas- y es índice de modalidad literal. Én estos casos, como vimos, el locutor apela a una tópica social que juzga ajenal, para refutarla con hechos.

Ya que contrastamos las paradojas umostradas» con las udichas» en función de su comportamiento respecto de la referencia, digamos (jue venimos entendiendo por tal el hecho ele (jue un texto o un enunciado se interpreten por relación a un proceso, situación o estado de cosas que se encuentran fuera del propio texto, tanto si son de naturalezat lingüística como extralingiiistica.

Pues bien, en el corpus examinado, la aparición de los activadores, marcas de la paradoja, va ligada en todos los casos a la existencia de una referencia empíricanente comprobable. Activadores, argumentación y referencia van unidos en todos los casos registrados. sin duda porque no liene objeco argumentar si no es con vistas a una práctica, inmediata o mediatla, (lel lipo que sea.

¿Cuál es la diferencia en los casos sin activadores" Recordemos, por un momento, un ejemplo de éstos frente a uno de los anteriores: los americanos, que, al abandonar lomejón, "se van pero se quedam», frente al coronel (iaddafi que, contra lo esperable, no apoyó a Sadam Husein. I.o (ue en este caso se afirma es, de acuerdo con la realidad empíricamente comprobable, que Gadelafi no apoyó a Saclam. Si reterencia y valor de verdad tienen alguma relación, no cabe duda de que la frase es verdadera, y que esa verdad se alcanza directamenc, como correspondencia entre el cnunciado y los hechos. Ahora bien, ies lo mismo para el otro caso? Sin duda, los americanos hau abandonado la base de Torrejón, pere jautorizalía eso a (leclarar lalsa la frase real e históricamente pronunciala por Manuel Gari, poltavo\% de la Comisión anti-()IAN, el 26 de marzo de 1992, y recogida en l:I Pais (lel día siguiente? Y nótese que no es lo mismo el hecho histórico de la salida de los americanos y el hecho de 
habla, asimismo puntual e irrepetible, de la frase pronunciadia al respecto, yue, por ejemplo. las expresiones abstraclas: "los americanos se vall pero alguien diee: "se vall pero se (pue(lann». De acpuélla. un receptor bienintencionado diría que corresponde a un cierto modo de ver los hechos con el yue se puede estar o no de acuerelo. Carecería de semtido plantear la cuestión de su verdad como acuerdo con los hechos. al margen de la perspectiva ideológiea det locutor y la modaliclacl expresival liguradia. Fn otras palablas, la referencia es açuí indirecta: no remile al hecho de que lon americanos se hayam ido, simo a mo modo de ver este hecho condicionado por un contexto ideológico implícito. De lo (pue no se infiere que las paradojas «dichas» sealn. en cambio, ideológicamente neutrales: revela en éstas la posición del atutor lo que él escoge como hecho incliscutible liente a lo (jue deja como implicación.

Fin nuestros análisis anteriores hemos hablado con frecuencia, sin rigor alguno, y ahora mismo acabamos de hacerlo, de sobreentendielos, presuposiciones o implicaturas, es decir, de partes del sentido no explícitas. peres imprescindibles para la construcción del sentido completo. Recordando el análisis de (irice", estamos ante «implicatturas conversacionales», lérmino (fue puede recubrir cómodamente cuantas suposiciones hemos necesilado para interpretar nuestros ejemplos.

(ince distingue frente a lats implicaturals conversacionales, otras, a las gue denomina convencionales, ejemplo de las colales es: "ll I say (smugly): "He is an tinglishman: tee is. therefore brave"»". Mientrats que, como ejemplo de las primeras: "Suppose that $A$ and $B$ are lalking about a mulual friend. $C$, who is now working in a bank. A alsks $B$ how $C$ is getting (on) in his job, and B replies, Oh quite well, I think: le likes his colleagues, and he hasn I been (o) prison yet's" Me parece claro que nuestros ejemplos no son ni tan convencionales como el del inglés. que por serto, es valiente. ni tan particulares como el del que trabaja en el banco, que recpuicre. arguye (irice. conoces a $C$ para decidir su interpretación.

Ambos lipos se oponen polarmente: uno corresponde a la conversación privada entre particulares, en teoria impredecible; el otro a ese conjunto de creencias sociales casi ritualizadats. Aloma bien, no sólo es posible encontrall no pocals convenciones y tópicos en la conversación particular, sino que entre ella y ese hablar casi rilual hay un amplísimo margen en la sociedad para un lenguaje que el formalismo de la leoría de Grice le impide consiclerar, por cjemplo, todo el recogido en la prensia diaria de la que procede nuestro corpus. Lats palabras y frases de ese lenguaje están parcialmente determinadlas por lactores (pue son: a) de naturaleza ideolégica, es decir. ideas sobre la sociedad y valores sociales que responden a lormas diversals de ver el mundo: $y$ b) supraindividuales, ya (pue sólo los grupos o clases sociales llegall a contrgurar ideologías.

P'ues bien, puesto yue estiblecer la relerencia de los entunciados paradójicos resulta operación inseparable de la recla interprelación de las implicalturas conversacionales, el contraste a estal luy de las paratejas dichas y las moctradas pucde contribuir a revelarnos un nuevo aspecto de su naturaley.

Como es sabide, el intercanbio conversacional se rige, según Grice, por un «Principio de Cooperakión», que se descompone en chatro categoríls de inspiración kantiana, de "canti-

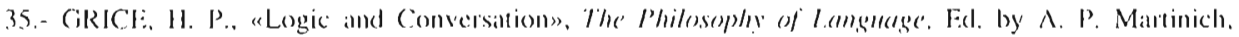
Oxford University Press. 1985 (primero publicalo en Symax and Semamics. vol. 3, ed. by Peler Cole and Jerry I. Morgan, Nueval York. Academic Press. 1975).

36.- ()p. cil., píg. 161 .

37.- Op. cil., píg. 160 . 


\section{PARA UNA RETOORICA DL̈ I.A PARADOJA}

dad» (que vuestra contribución sea tan informativa como se requicra pero no más): "cuali-

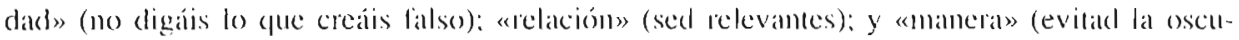
riclad, ambiguiedacl, prolijiclad...).

Podemos prescindir apuí de la interminable discusión crítica a propósito de las máximas de Grice y lijarmos simplemente en que, desde un punto de vista pragmático, las paltadojals "dichas», como más amiba hemos apuntado, dicen menos de lo necesario, pero el receptor del mensaje lo suple sin problemas apelando a creencian sociales. Las paradojas «mostandas», al contrario, no sólo diecen menos de lo preciso, sino que incumplen además las máximas de manera: son expresiones oscurals. que parecen falsas, por lo que el receptor. suponiendo que su interlocutor respela lats maximas de cualidad, se ve obligado a construir una interpretación consistente con éstas. Así aparece, en el sistema de (irice, la diferencia entre literalidad y fïguración: la paradoja en lenguaje literal, al servicio del análisis y la angumentación. liente a la segunda que. pudiendo servir a ésta, añale la tensión expresiva propia del lenguaje fïgurado.

En la relación con (ue abríamos esta sección registrábamos la presuposicion existencial fen senticle (le Frege), que conviene distingamos de las implicaturas conversacionales. I al presuposición existencial representa, a mi entender, la vertiente lógical del problema de las callegorías lingiifsticals. Si se piensall éstas como "modos significativos del hablat" ", lat caltegoría «sustantivo» permite concebir la realidad como «ser en sím, y entonces lo significardo por un nombere produce la ilusión de existir, propiedad que, a cambio de producir no poess quebraderos de cabezal a los lógicos. permite a Don Quijote seguirse patseande entre nosotros. Así que, como ocurria en los ejemplos de J. V. Marqués cilados, deste el momento en que introducimos en el (liscurso lérminos nomimales, como "l)ios" " «intelectual», creamos la ilusión de su existencia, y jugando a negarla, produciremos expresiones paradójicas: ael no ser liene que ser de alguna manera, pues, de otre modo, iqué es lo que no es? F.sta enreclosa doctrina puede ser apodada la barbe de Platom. la lal barba ha probirko históricamente su vigor mellando más (le tma ve\% el filo de la navaja de Occamm" "s.

Finalmente. digamos unas pocas palabras sobre los vitiles gramaticales de la paradoja. De entrada. un estudio como la ya clásica A (jremmer of Melaphor. de Christine Brooke-Rose "t. resulta apuí imposible. I as paratojals no se confinan en el espacio de una oración gramatical. simple o compleja, y su presencia no está ligada a un lipo de construceiones sintácticas en particular. No obstante, puede decirse que hady ciertas formats que lavorecen la expresión paradójica, y supuesto yue lo que define a la paradojas es la fommlacion de una incompatibiliclad, aparecerán en ellas cuanlas unidades de la lengua se presten particularmenle a expresar ésta:

- midades léxicas en relación de antonimia;

la negación bajo loclas sus formas;

- moricmas que expresen polaridad, por cjemplo: uno/varios;

- oraciones preferentemente adversaltivas y condicionales.

Ahora podemos sintetizar cuantos tipos hemos analizado hasta el momento:

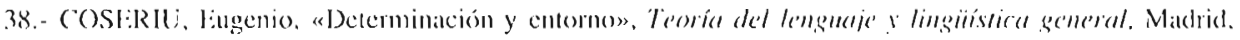
Gredes, 1967 (primero publicado en Rememistisches Jambuch. VII, 1955-56), píg. 288.

39.- QUINE: Willard Van Orman, "Acerca de lo que hay". Desele um pumbo de visto lógico. (trad. de M. Sacristán), Barcelona. Ariel, 1962, pág. 20.

40.- BROOKE-ROSI:, Christine, A Cirammar of Metaphor, londres, Secker and Warburg, 1958. 
FERNANDO ROMO

$\begin{array}{lcccccc}\quad \text { lipo } & \text { dichal } & \text { mostradla } & \text { ref. direcli } & \text { indirecta } & \text { literal } & \text { figurada } \\ \text { disociativas } & + & - & + & - & + & - \\ \text { decir/hacer } & - & + & + & & + & - \\ \text { promedian } & & + & - & + & & + \\ \text { disocian } & - & + & & + & - & + \\ \text { figuradias } & - & + & & + & & + \\ \text { c. vicioso } & & + & - & + & - & + \\ \text { pres. exist. } & - & + & & + & - & +\end{array}$

Li primer tipo citado es el que se sirve de activadores y el segundo el que responde al lópico aristotélico (que consiste en oponer el decir al hacer o el decir público al privado; atun(jue aquí no haly melalenguaje, por ko que la paratloja debe revelar por sí su naturaleza, son éstas tan disociativas y tan eficaces en la argumentación como las primerals. I.os tres tipos siguientes corresponden a los aislactos por Norrick y como una subclase aislata por nosotros están las (que niegan la presuposición existencial. I cos dós primeros tipos son los más puramente analíticos y los cinco últimos los que claramente entran en el Ienguaje ligurado; mientras que el tipo «decir/hacer». anmeque sín expresiones metalingiísticals, opera con referencia directa como el primero y suele ocurit en textos extensos.

Añadamos, finalmente, que nuestra relación se sabe no exhatustiva, pero al menos supone creo- un primer paso en el análisis de este escunema, tal como se da en el hablar real. 